Review/Meta-analyses

\title{
Effects of stimulant drug use on the dopaminergic system: A systematic review and meta-analysis of in vivo neuroimaging studies
}

\author{
Lisa Proebstl ${ }^{\mathrm{a}, *}$, Felicia Kamp ${ }^{\mathrm{a}}$, Kirsi Manz ${ }^{\mathrm{b}}$, Daniela Krause ${ }^{\mathrm{a}}$, Kristina Adorjan ${ }^{\mathrm{a}}$, \\ Oliver Pogarell ${ }^{\mathrm{a}}$, Gabi Koller ${ }^{\mathrm{a}}$, Michael Soyka ${ }^{\mathrm{a}, \mathrm{c}}$, Peter Falkai ${ }^{\mathrm{a}}$, Joseph Kambeitz ${ }^{\mathrm{a}}$ \\ a Department of Psychiatry and Psychotherapy, Ludwig-Maximilians-University, Munich, Germany \\ ${ }^{\mathrm{b}}$ Institute for Medical Information Processing, Biometry, and Epidemiology, LudwigMaximilians-University, Munich, Germany \\ ${ }^{c}$ Medical Parc Chiemseeblick, Bernau am Chiemsee, Germany
}

\section{A R T I C L E IN F O}

\section{Article history:}

Received 18 January 2019

Received in revised form 13 March 2019

Accepted 17 March 2019

Available online 11 April 2019

\section{Keywords:}

Amphetamines

Cocaine

Nicotine

Neuroimaging

PET

SPECT

Neurotransmitters

Dopamine

Striatum

DAT

\begin{abstract}
A B S T R A C T
Background: Stimulant drugs can cause persistent changes in the brain. Imaging studies show that these changes are most apparent in dopamine transporter (DAT) or receptor availability within the striatum. Methods: This work focuses on influences of stimulant use on dopaminergic function assessed using nuclear-medicine imaging (PET/SPECT). Included are 39 studies on 655 cocaine, amphetamine, methamphetamine or nicotine users, as well as 690 healthy controls. Metaanalyses were conducted separately for D2/D3 receptors and dopamine transporters of the entire striatum, its subregions caudate and putamen respectively.

Results: Meta-analyses results regarding nicotine did not show significant effects between smokers and nonsmokers. In cocaine users there was a significant decrease in dopamine receptor availability in all regions. The striatal DAT availability was significantly increased in cocaine users. Methamphetamine users showed a significantly decreased dopamine receptor and transporter density in all regions. Significant results also indicate a lower transporter availability in all regions. Amphetamine users showed reduced DAT availability in the striatum, as well as in the sub regions.

Conclusion: This meta-analysis provides evidence that there are ongoing changes in the dopaminergic system associated with the use of stimulants. Especially the results of cocaine, methamphetamine and amphetamine use mainly showed a downregulation. In addition, this meta-analysis is the first to include nicotine. This subset of studies showed evidence for a decreased receptor and DAT availability but no significant results were found in the metaanalyses.
\end{abstract}

(c) 2019 Elsevier Masson SAS. All rights reserved.

\section{Introduction}

Drug use is an ongoing worldwide problem, especially the use of stimulant substances has increased [1].The lifetime prevalence for relevant substances rose from $3.6 \%$ in 2016 to $3.8 \%$ in 2017 for a population aged 15-64 in the European Union (EU) [2]. A 12month prevalence for the use of amphetamines in the $\mathrm{EU}$ is $0.5 \%$ for

\footnotetext{
* Corresponding author at: Department of Psychiatry and Psychotherapy, LMU University of Munich, Nußbaumstrasse 7, 80336 Munich, Germany.

E-mail addresses: lisa.proebstl@med.uni-muenchen.de (L. Proebstl), Felicia.kamp@med.uni-muenchen.de (F. Kamp), manz@ibe.med.uni-muenchen.de (K. Manz), Daniela.Krause@med.uni-muenchen.de (D. Krause),

Kristina.Adorjan@med.uni-muenchen.de (K. Adorjan), Oliver.Pogarell@med.uni-muenchen.de (O. Pogarell),

gabi.koller@med.uni-muenchen.de (G. Koller),m.soyka@medicalpark.de

(M. Soyka), Peter.Falkai@med.uni-muenchen.de (P. Falkai),

Joseph.Kambeitz@med.uni-muenchen.de (J. Kambeitz).
}

adults and $1.1 \%$ for adolescents [2]. Methamphetamine (MA) is a synthetically compounded amphetamine derivate which is biologically more active than amphetamine [3] with a longer half-life period [4]. Thus the substance has a prolonged duration of action on the brain [5]. Cocaine is also an amphetamine-type drug, it is the second most used illegal drug and the most used stimulant substance within the EU with a lifetime prevalence of $5.2 \%$ for adults [2]. Nicotine, ingested through smoking has been and continues to be a global health problem [6]. This substance stimulates the brain in a similar way as the above mentioned substances [7-9]. The activation of nicotinic acetylcholine receptors leads to changes in the synaptic cleft [10] thereby increasing dopamine levels [11]. Through smoking the dopamine release is also modulated by the activation of nicotine receptors in the striatum. This effect in addition to the dopamine transmitter metabolism inhibition through stimulant drugs leads to an increased dopamine release and a simultaneous reduction of reuptake [3]. Stimulant use causes an unbalanced dopaminergic 
system, which leads to alterations and impairments in the reward system and circuits. This change in the reward system combined with withdrawal symptoms is one reason for symptoms of addiction [12]. Imaging studies with positron emission tomography (PET) or single photon emission computerized tomography (SPECT) have found differences between stimulant users and healthy controls [e.g. 13,14].

Research comparing current nicotine dependent smokers and nonsmokers yielded mixed results. For example some publications reported lower dopamine transporter (DAT) activity in the left putamen and right caudate in smokers [8], or lower dopamine receptor density in male smokers only $[15,16]$, while Dagher et al. [17] reported significantly lower receptor density in smokers' striatum and its subregions. Other studies reported no differences in DAT [18] or receptors [19] in current smokers. Inconsistent results were also found between current cocaine users compared to healthy controls indicating lower DAT and receptor density in cocaine dependents [20-22] and abusers [23] or higher DAT in dependents [24-26] or no differences in dependent subjects [27-29] and cocaine users [30] compared to the control groups. Compared to healthy controls, evidence for significantly reduced DAT and receptors in MA users were found in some studies for currently MA dependent subjects [31-34], current MA abusers [35-37], chronic users [38] and former users or MA dependent subjects in rehabilitation [39-43]. However, Volkow et al. [44] found a trend for lower DAT levels in current MA dependents and abusers, while Iyo et al. [45] reported no differences in receptor levels between males with a history of MA abuse and healthy controls. For amphetamines, most studies report significantly decreased DAT in abstinent heavy users [46] and decreased receptor levels in recreational [47] or former users [48] compared to healthy controls. Other studies show a negative trend [47] or no changes in recreational users [49] compared to healthy controls. In summary, it appears that present research shows inconsistent results in regard to changes to the dopaminergic system due to stimulant substance abuse.

Continuing from work in a previously published analysis examining the effects of stimulants on the striatum, excepting nicotine [50], this meta-analysis summarizes results from previously published studies investigating the effects of individual stimulants (cocaine, MA, amphetamines, nicotine), on the dopaminergic system for the whole striatum. More detailed results for the striatal subregions caudate and putamen were also included. Smoking (i.e. nicotine) was allowed in most of the study groups and could have influenced the measurements. Therefore, metaanalyses on nicotine were also conducted to summarize its possible effects. The aim of this analysis was to examine differences between users and nonusers of stimulating substances and whether these substances differ in their effects on the dopamine system's function in the striatum.

\section{Methods}

\subsection{Literature search and data extraction}

A comprehensive literature search was conducted via the electronic database PubMed with the following search term: ("stimulant*" OR "psychostimulant*" OR "amphetamine*" OR "methamphetamine" OR "speed" OR "crystal meth" OR “Nmethylamphetamine" OR

"nicotine") AND (“dopamine" OR “DA") AND (“D2" OR “DAT” OR "D3" OR "D2/D3" OR

"D2/3" OR "presynaptic" OR "FDOPA" OR "F-DOPA" OR "synthesis") AND ("pet" OR "spect"

OR "positron emission" OR "single photon emission" OR "tomography") AND
("1950/01/01"[PDAT] : "2016/06/31"[PDAT]) to identify neuroimaging studies using PET or SPECT to investigate DAT or dopamine receptor $\left(D_{1}, D_{2}, D_{3}\right)$ availability in stimulant users, which were in English, no single case studies or reviews. The search was conducted by two authors (L.P., F.K.) independently, results were compared and a consensus was achieved if needed via detailed discussion. Included studies had a group of stimulant users (methamphetamine, amphetamine, cocaine, nicotine) and a control group (no lifetime diagnosis of any drug use), and all participants should be at least 18 . The following information was extracted from the included studies: age, sex, number of participants per group, abused drugs, nicotine consumption, potential duration of abstinence in the user group, brain region for which results were reported and type of radioligand. When studies reported a range of abstinence duration, the mean of minimum and maximum was calculated as an indicator of the mean abstinence time. Included publications were divided into the four substance groups for which meta-analyses were calculated separately. Means and standard deviations (SD) were extracted to calculate the effect sizes of differences in dopaminergic imaging parameters. If individual studies reported other variables these were converted to the above reported value formats using a formula reported in the supplementary documentation. Duration of abstinence was reported in different formats, to achieve a uniform format one month was considered as 30 days. Current users were recorded as having 0 days of abstinence and means were used for calculations. When studies reported results of more than one scan, baseline results were extracted.

For the main outcome measures different parameters were used. Several measures of binding potential (BP) $\left(\mathrm{BP}, \mathrm{BP}_{\mathrm{ND}}, \mathrm{B}_{\max } /\right.$ $\mathrm{k}_{\mathrm{D}}$ ) were included, which represent the uptake of the radioligand in the brain and indicate the affinity on the structures of interest [51]. Other measuring methods represent the uptake rate constant for the transport of the tracer from plasma to a free ligand compartment in tissue, which is called $K_{1}$ and related rate constants which are all comparing influx constants in the region of interest $\left(\mathrm{K}_{2}, \mathrm{~K}_{3}, \mathrm{~K}_{4}, \mathrm{Kd} \mathrm{re}_{\mathrm{i}}\right)$ [51,52]. All included studies concentrated on BPs of a tracer in the dopaminergic system, which makes them comparable because of their same direction of the scales [53]. An overview about the different used radioligands is provided in Table 1.

\subsection{Data analysis}

Analyses were conducted for different substances and brain regions using the metafor package [54] in $\mathrm{R}$ (Version 3.5.0). A random effects model with derSimonian-Laird variance estimator with inverse variance weighting was used to pool the data. Effect sizes (Hedge's g) were calculated for differences in BPs between users and controls. The main outcome measure was the difference in dopaminergic imaging parameters between the groups. The summary estimates are reported with their 95\% confidence intervals $(\mathrm{CI})$.

\section{Results}

Moderation analyses were calculated for year of publication, average age, gender distribution, imaging method and durations of abstinence by including the corresponding moderator variables into the random effects model one by one. The significance was judged based on the $\mathrm{p}$ value of the test of moderators in the model. In order to avoid very unstable estimates providing only limited utility the moderator analysis was only conducted if the number of the studies included was greater than three. To evaluate potential publication bias, Egger's regression tests for funnel plot asymmetry [55] were conducted, the minimum number of studies required for 
Table 1

Characteristics of participants, nicotine statuses, used radioligands and imaging methods of all included studies.

\begin{tabular}{|c|c|c|c|c|c|c|c|c|c|c|c|}
\hline \multirow[t]{2}{*}{ author(s) } & \multirow[t]{2}{*}{ structure } & \multirow[t]{2}{*}{ tracer/ method } & \multicolumn{2}{|c|}{ control group } & \multicolumn{7}{|c|}{ patient group } \\
\hline & & & $\begin{array}{l}\mathrm{n} \\
\text { (males) }\end{array}$ & age & $\begin{array}{l}\mathrm{n} \\
\text { (males) }\end{array}$ & age & substance & $\begin{array}{l}\text { days of } \\
\text { abstinence } \\
\text { (minimum/ } \\
\text { mean) }\end{array}$ & $\begin{array}{l}\text { Nicotine } \\
\text { allowed }\end{array}$ & $\begin{array}{l}\text { dose } \\
\text { (mean) }\end{array}$ & $\begin{array}{l}\text { duration } \\
\text { of } \\
\text { use } \\
\text { (mean) }\end{array}$ \\
\hline Ballard et al. [31] & $\mathrm{D}_{2} / \mathrm{D}_{3}$ & 18-F-fallypride/ PET & $27(11)$ & 35.4 & $27(16)$ & 33.3 & MA & $4 / 5.5$ & yes & $2.7 \mathrm{~g}$ & 9.1 years \\
\hline Ballard et al. [33] & D2/D3 & 18-F-fallypride/ PET & $18(11)$ & 36.4 & $18(10)$ & 33.1 & MA & $4 / 5.5$ & yes & $2.8 \mathrm{~g}$ & 9.3 years \\
\hline Lee et al. [32] & $\mathrm{D}_{2} / \mathrm{D}_{3}$ & 11-C-PHNO/ PET & $30(16)$ & 34.9 & $22(13)$ & 35.6 & MA & $4 / 10$ & yes & NA & NA \\
\hline Schrantee et al. [47] & $\mathrm{D}_{2} / \mathrm{D}_{3}$ & 123I-IBZM/ SPECT & $20(20)$ & 21.1 & $15(15)$ & 21.1 & $\begin{array}{l}\text { Dexamph } \\
\text { etamine }\end{array}$ & $7 / 7$ & $24 \mathrm{~h}$ not & $0.25 \mathrm{~g}$ & NA \\
\hline Schrantee et al. [48] & $\mathrm{D}_{2} / \mathrm{D}_{3}$ & 123I-IBZM/ SPECT & $18(14)$ & 21.0 & $20(17)$ & 21.0 & Ampheta mine & $7 / 7$ & $24 \mathrm{~h}$ not & $0.25 \mathrm{~g}$ & 2.5 years \\
\hline Wiers et al. [23] & $\mathrm{D}_{2} / \mathrm{D}_{3}$ & 11-C-raclopride/ PET & $42(38)$ & 43.9 & $38(34)$ & 42.2 & cocaine & NA & yes & $3.31 \mathrm{~g}$ & 17.47years \\
\hline Matuskey et al. [30] & $\mathrm{D}_{2} / \mathrm{D}_{3}$ & 11-C+PHNO/ PET & $16(13)$ & 40.3 & $16(12)$ & 41.9 & cocaine & NA/NA & yes & NA & 19.9 years \\
\hline Martinez et al. [21] & $\mathrm{D}_{2} / \mathrm{D}_{3}$ & 11-C-raclopride/ PET & $24(21)$ & 36.0 & $25(22)$ & 37.0 & cocaine & $14 / 14$ & yes & NA & NA \\
\hline Narendan et al. [28] & $\mathrm{D}_{2} / \mathrm{D}_{3}$ & 11-C-raclopride/ PET & $10(7)$ & 42.0 & $10(7)$ & 44.0 & cocaine & $14 / \mathrm{NA}$ & yes & NA & NA \\
\hline Martinez et al. [22] & $\mathrm{D}_{2} / \mathrm{D}_{3}$ & 11-C-raclopride/ PET & $15(13)$ & 39.0 & $15(13)$ & 39.0 & cocaine & $14 / 14$ & yes & NA & 13.5 years \\
\hline Martinez et al. [20] & $\mathrm{D}_{2} / \mathrm{D}_{3}$ & 11-C-raclopride/ PET & $17(13)$ & 38.5 & $17(13)$ & 38.7 & cocaine & $14 / 14$ & yes & NA & NA \\
\hline Brown [15] & $D_{2} / D_{3}$ & 18-F-fallypride/ PET & $18(9)$ & 31.6 & $19(10)$ & 36.4 & nicotine & $0 / 0$ & - & $\begin{array}{l}4-14 \mathrm{cig} / \\
\mathrm{d}\end{array}$ & NA \\
\hline Yang et al. [16] & $\mathrm{D}_{2} / \mathrm{D}_{3}$ & 99mTc TRODAT-1/ SPECT & $11(11)$ & 27.1 & $11(11)$ & 28.7 & nicotine & $0 / 0$ & - & NA & NA \\
\hline Yang et al. [19] & $\mathrm{D}_{2} / \mathrm{D}_{3}$ & 123I-IBZM/ SPECT & $15(15)$ & 33.2 & $15(15)$ & 33.3 & nicotine & $0 / 0$ & - & $18 \mathrm{cig} / \mathrm{d}$ & NA \\
\hline Okita et al. [34] & $\mathrm{D}_{2}$ & 11-F-fallypride/ PET & $17(9)$ & 32.1 & $23(15)$ & 35.6 & MA & NA/NA & yes & NA & NA \\
\hline Wang et al. [65] & $\mathrm{D}_{2}$ & 11-C-raclopride/ PET & $15(13)$ & 37.2 & $16(13)$ & 39.2 & MA & 14/NA & yes & NA & $\geq 1$ year \\
\hline Iyo et al. [38] & $\mathrm{D}_{2}$ & 11-C-N-methylspiperone/ PET & $10(10)$ & 28.8 & $6(6)$ & 28.0 & MA & $30 / \mathrm{NA}$ & NA & NA & NA \\
\hline Matuskey et al. [27] & D3 & $11-\mathrm{C}+\mathrm{PHNO} / \mathrm{PET}$ & $10(8)$ & 41.0 & $10(8)$ & 41.0 & cocaine & NA/90 & yes & NA & NA \\
\hline Salokangas et al. [8] & $\begin{array}{l}\text { Dopamin } \\
\text { e activity }\end{array}$ & & $10(10)$ & 37.1 & $9(9)$ & 36.8 & nicotine & $0 / 0$ & - & $19.8 \mathrm{cig} / \mathrm{d}$ & 19.8 years \\
\hline McCann et al. [39] & DAT & 11-C-Win-35,428/ PET & $10(4)$ & 30.5 & $6(3)$ & 31.2 & MA & NA/NA & NA & $0.83 \mathrm{~g}$ & 11.2 years \\
\hline Volkow et al. [44] & DAT & 11-C-raclopride/ PET & $15(13)$ & 37.2 & $16(13)$ & 39.2 & MA & $14 / \mathrm{NA}$ & yes & NA & $\geq 1$ year \\
\hline Sekine et al. [36] & DAT & 11-C-Win-35,428/ PET & $9(9)$ & 26.9 & $11(11)$ & 27.4 & MA & $7 / 277.3$ & no & NA & 4.8 years \\
\hline Volkow et al. [43] & DAT & $\begin{array}{l}\text { 11-C-d-threo- } \\
\text { methylphenidate/ PET }\end{array}$ & $18(12)$ & 31.0 & $15(6)$ & 32.0 & MA & 14/NA & NA & $1.6 \mathrm{~g}$ & 11 years \\
\hline Iyo et al. [38] & DAT & 11-C-Win-35,428/ PET & 9 (NA) & 26.9 & $11(\mathrm{NA})$ & 27.4 & MA & $56 / 56$ & NA & NA & NA \\
\hline Chou et al. [37] & DAT & Tc-99nm-Trodat/SPECT & $7(7)$ & 24.0 & $7(7)$ & 23 & MA & NA/NA & yes & NA & 7.7 years \\
\hline Yuan et al. [41] & DAT & 99m-Tc-TRODAT-1/SPECT & $25(14)$ & 32.0 & $25(17)$ & 30.6 & MA & $2 / 2$ & NA & $0.94 \mathrm{~g}$ & 4.09 years \\
\hline Yuan et al. (2017) & DAT & 99m-Tc-TRODAT-1/SPECT & $21(14)$ & 30.6 & $25(17)$ & 30.6 & MA & $14 / 14$ & yes & $0.8 \mathrm{~g}$ & 4.3 years \\
\hline Johanson et al. [46] & DAT & 11-C-MPH/ PET & $16(10)$ & 31.0 & $15(11)$ & 32.0 & Ampheta mine & $30 / \leq 365$ & yes & NA & $\geq 3$ month \\
\hline Schouw et al. [49] & DAT & 123IFP-CIT/ SPECT & $10(8)$ & 23 & $10(8)$ & 26 & $\begin{array}{l}\text { Dexamph } \\
\text { etamine }\end{array}$ & $14 / 14$ & yes & NA & $\geq 40$ uses \\
\hline Wang et al. [35] & DAT & 11-C-cocaine/ PET & $11(9)$ & 33.2 & $18(6)$ & 30.9 & $\begin{array}{l}\text { Methylph } \\
\text { enidate }\end{array}$ & $1 / 1$ & yes & NA & NA \\
\hline $\begin{array}{l}\text { Crits-Cristoph et al. } \\
\text { [24] }\end{array}$ & DAT & 99m-Tc-Trodat-1/ SPECT & $21(14)$ & 40.3 & $21(16)$ & 42.8 & cocaine & NA/NA & yes & NA & 11.7 years \\
\hline Jacobsen et al. [25] & DAT & $123 \mathrm{I}-\beta-\mathrm{CIT} / \mathrm{SPECT}$ & $37(20)$ & 35.8 & $15(10)$ & 33.7 & cocaine & NA/3.7 & NA & $\begin{array}{l}5.2 \mathrm{~g} / \\
\text { week }\end{array}$ & 13 years \\
\hline Malison et al. [26] & DAT & 123I- $\beta-\mathrm{CIT} / \mathrm{SPECT}$ & $24(15)$ & 33.0 & $28(18)$ & 32.0 & cocaine & NA/NA & NA & $\begin{array}{l}30 \mathrm{~g} / \\
\text { month }\end{array}$ & NA \\
\hline Wang et al. [29] & DAT & C-11-cocaine/ PET & $20(18)$ & 36.6 & $20(15)$ & 36.2 & cocaine & $0 / 0$ & yes & $4 \mathrm{~g} /$ week & NA \\
\hline Staley et al. [18] & DAT & 18-F-fallypride/ PET & $21(9)$ & 40.0 & $21(9)$ & 40.4 & nicotine & $0 / 0$ & - & $\geq 15 \mathrm{cig} / \mathrm{d}$ & NA \\
\hline
\end{tabular}

the analysis was three. The significance level for all analyses in this work was set at $\mathrm{p}=0.05$.

After an initial identification of 880 articles using the above defined search criteria, 841 articles were excluded which resulted in 39 articles that were included in quantitative metaanalyses. The articles in the analysis compared 655 users with 690 controls. Some studies provided more than one sample for calculations (e.g. more than one region, for DAT and receptors) [16,20,21,23, $24,27,28,30,32,35,39,41-43,46,49]$. Samples were separated by substance, which resulted in 29 samples for quantitative analyses of methamphetamine out of 15 studies, 26 samples for cocaine out of 12 studies, 11 samples for amphetamines out of 5 studies and 9 samples for nicotine out of 6 studies. Schouw et al.

[49] presented their results graphically, here means and SD's were estimated by using Web Plot Digitizer 3.10 [56]. Three studies [31-33] provided standard errors, which were calculated into SD's. Some studies provided means and SD's of caudate and putamen, which were summarized into data for the dorsal striatum
$[23,29,35,44]$ or the whole striatum $[8,15,17,21,27,30$, $32,36,38,39,42,43]$. Others provided separate results for the left and right hemispheres [37,40,41], here the means and SD's were summarized.

The majority of participants did not suffer from any psychiatric disorder, except drug abuse or dependence in the user group, or any physiological disease in both groups. Control group participants were mainly healthy controls with no history of drug use, or reported relevant comorbidities potentially influencing dopaminergic metabolism (e.g. schizophrenia, parkinson's disease or ADHD), and most of the participants were allowed to consume nicotine and alcohol. As there were not enough studies to conduct analyses with nonsmoking, stimulant drug using participants, smoking was allowed in most of the included groups, except Schrantee et al. [48] and the nicotine control groups [8,15-19]. In two studies some or all substances users also had a diagnosis of ADHD [25,35], see Table 1 for further listings of study group compositions. 


\subsection{Nicotine}

In total $\mathrm{k}=4$ studies were included comprising $\mathrm{N}=56$ smokers and $N=62$ nonsmokers for the analysis of the $D_{2} / D_{3}$ receptor availability in the striatum. The meta-analysis showed no significant changes in dopamine receptor density with an effect size of $g=-1.03(95 \% \mathrm{CI}$ : [-2.58, 0.51], $\mathrm{p}=0.19)$, see Fig. 1 . There was no evidence for publication bias $(p=0.16)$, or moderation effects for year of publication $(p=0.08)$, age $(p=0.68)$, gender $(p=0.14)$ or used method $(p=0.12)$.

A number of $\mathrm{k}=3$ studies was used for the meta-analysis of striatal DAT in smokers vs. nonsmokers. A comparison of $\mathrm{N}=41$ smokers with $\mathrm{N}=42$ healthy controls did not show a significant effect with $g=-0.05(95 \% \mathrm{CI}$ : $[-1.16,1.05], \mathrm{p}=0.93)$, see Fig. 1 . There was no evidence for publication bias $(p=0.96)$, but the calculation of a regression test for funnel plot asymmetry tends to be unreliable with $\mathrm{k}=3$ studies only. Moderation effects were not calculated because of the small number of studies.

No meta-analyses were calculated for the sub regions caudate and putamen within smokers and nonsmokers, because only Brown provided data for the subregion caudate, see Fig. 1 for further details.

\subsection{Cocaine}

Starting with analyses for the whole striatum, a number of $\mathrm{k}=7$ studies with $\mathrm{N}=131$ users and $\mathrm{N}=134$ controls met the inclusion criteria for the $D_{2} / D_{3}$ receptor availability. The summarized effect size was significant with $\mathrm{g}=-0.76(95 \% \mathrm{CI}$ : $[-1.18,-0.34], \mathrm{p}<0.01)$, see Fig. 2 , indicating a lower $D_{2} / D_{3}$ receptor density in users. There was no evidence for publication bias $(p=0.26)$, or moderation effects for year of publication $(p=0.30)$, age $(p=0.99)$ or gender $(p=0.50)$ without effects.

In total $\mathrm{k}=4$ studies were included, comprising $\mathrm{N}=84$ users and $\mathrm{N}=102$ controls for DAT availability in the whole striatum. The summarized effect size was significant with $g=0.66$ (95\% CI: [0.30, 1.02 ], $\mathrm{p}=<0.01$ ), see Fig. 2 . This indicates a higher DAT availability in consumers. There was no evidence for publication bias $(p=0.98)$, or moderation effects for year of publication $(p=0.37)$, age $(p=0.96)$ and gender $(p=0.48)$. A moderation effect of used method was found $(p=0.04)$, SPECT yielded in higher positive effects than PET.
Further analyses were conducted for the subregion caudate. To calculate the $D_{2} / D_{3}$ receptor availability $k=7$ studies with $N=131$ users and $\mathrm{N}=134$ controls were included. The summarized effect size was significant with $\mathrm{g}=-0.54(95 \% \mathrm{CI}$ : $[-0.78,-0.29], \mathrm{p}=<0.01)$, see Fig. 2. This effect indicates a lower $D_{2} / D_{3}$ receptor availability in the caudate of cocaine consumers compared to controls. There was no evidence for publication bias $(p=0.53)$, or moderation effects for year of publication $(p=0.30)$, age $(p=0.22)$, gender $(p=0.21)$. For the analysis of DAT availability only one study with $\mathrm{N}=21$ cocaine users and $\mathrm{N}=21$ healthy controls was included, which made it impossible to calculate a summarized effect. The study revealed a standardized mean difference (SMD) of $0.94,95 \%$ CI: $[0.30,1.58]$ for caudate DAT indicating higher dopamine transporter availability in cocaine users compared to controls.

Further analyses were calculated for the subregion putamen. For the analysis regarding $D_{2} / D_{3}$ receptor availability $k=6$ studies with $\mathrm{N}=116$ users and $\mathrm{N}=119$ controls were included. The summarized effect size was significant with $\mathrm{g}=-0.88$ (95\% CI: $[-1.15,-0.61], \mathrm{p}=<0.01)$, see Fig. 2 . This effect indicates a lower $\mathrm{D}_{2} /$ $D_{3}$ receptor availability in the putamen of cocaine consumers compared to controls. There was no evidence for publication bias $(p=0.93)$, or moderating effects for year of publication $(p=0.96)$, age $(p=0.26)$, gender $(p=0.34)$ or used method $(p=0.73)$. A moderation effect was found for minimal duration of abstinence $(p<0.01)$ with a lower density found for an increasing duration of abstinence. For the analysis of DAT availability in the putamen only one study with $\mathrm{N}=21$ users and $\mathrm{N}=21$ controls was included, for this reason no summary estimate was calculated. The result of this study was $\mathrm{SMD}=2.77,95 \% \mathrm{CI}$ : $[1.90,3.64]$ for putamen DAT indicating higher dopamine transporter availability in cocaine users compared to controls.

\subsection{Methamphetamine}

For the analyses of the whole striatum $\mathrm{k}=7$ studies investigating the $D_{2} / D_{3}$ Receptor availability were included regarding $N=127$ users and $\mathrm{N}=137$ controls. The summarized effect size was significant with $\mathrm{g}=-0.77$ (95\% CI: [-1.03, -0.52]. $\mathrm{p}<0.01$ ), see Fig. 3. This effect indicates a lower $D_{2} / D_{3}$ receptor availability in the striatum of MA consumers compared to controls. There was no evidence for publication bias $(p=0.35)$ and no moderation effects of year of publication $(p=0.68)$ or age $(p=0.77)$.

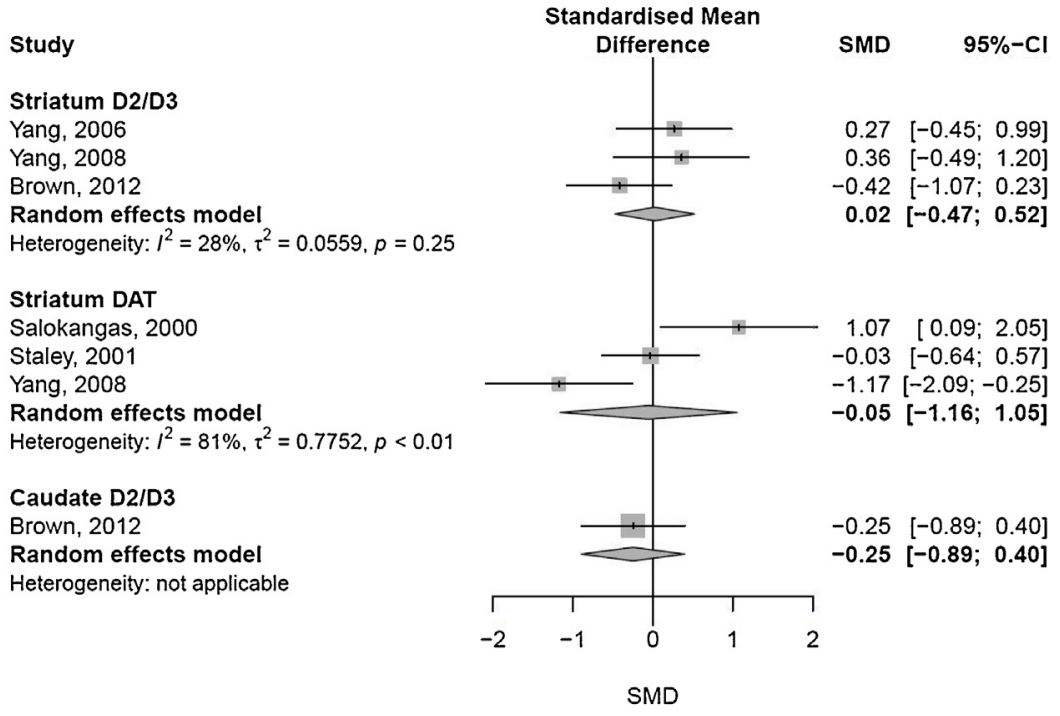

Fig. 1. Forest plot of meta-analysis of striatal dopaminergic function in smokers vs. nonsmokers. 


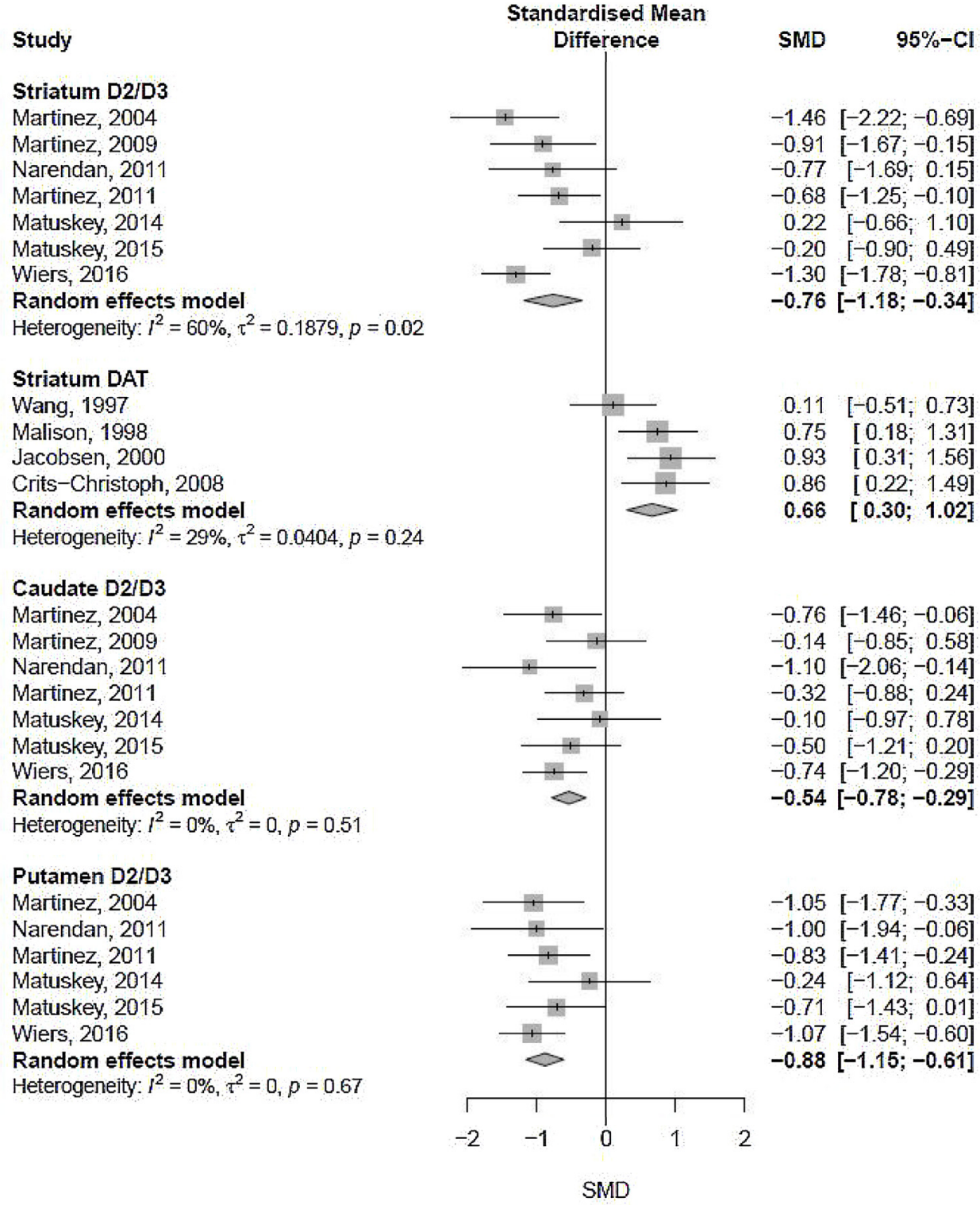

Fig. 2. Forest plot of meta-analysis of striatal dopaminergic function in cocaine users.

In total $\mathrm{k}=7$ studies comprising $\mathrm{N}=91$ users and $\mathrm{N}=93$ controls were included for the analysis of striatal DAT availability. The summarized effect size was significant with $\mathrm{g}=-1.50$ (95\% CI: [-2.65, -0.34], $p=0.01$ ), see Fig. 3. This effect indicates a lower DAT availability in the striatum of MA consumers compared to controls. There was no evidence for publication bias $(p=0.14)$, or moderation effects for year of publication $(p=0.12)$, age $(p=0.42)$ and used method $(p=0.31)$. For caudate, a number of $k=3$ studies were included regarding $D_{2} / D_{3}$ receptor availability in $N=53$ users and $\mathrm{N}=65$ controls. The summarized effect size was significant with $\mathrm{g}=-0.70(95 \% \mathrm{CI}:[-1.08,-0.32], \mathrm{p}<0.01)$, see Fig. 3. This effect indicates a lower $D_{2} / D_{3}$ receptor availability in the caudate of MA consumers compared to controls. There was no evidence for publication bias $(p=0.53)$ and no moderation effects for year of publication $(p=0.30)$, age $(p=0.22)$, gender $(p=0.21)$ or minimal duration of abstinence $(\mathrm{p}=0.71)$.

In total $\mathrm{k}=4$ studies with $\mathrm{N}=62$ users and $\mathrm{N}=64$ controls met the criteria for an analysis of DAT availability. The summarized effect size was significant with $\mathrm{g}=-2.09$ (95\% CI: [-2.82, -1.37], $\mathrm{p}<0.01$ ), see Fig. 3 . This effect indicates a lower DAT availability in the caudate of MA consumers compared to controls. There was no evidence for publication bias ( $p=0.94)$, no moderation effects were found for age $(p=0.82)$, gender $(p=0.07)$, used method $(p=0.81)$ or minimal duration of abstinence $(p=0.08)$. A small moderation effect was found for year of publication $(p=0.03)$ pointing to stronger negative effects with increasing year of publication. Further analyses were calculated for putamen. To conduct the $D_{2} /$ $D_{3}$ receptor availability $k=3$ studies were included regarding $\mathrm{N}=53$ users and $\mathrm{N}=65$ controls. The summarized effect size was significant with $g=-0.47$ (95\% CI: [-0.93, -0.02], $\mathrm{p}=0.04$ ), see Fig. 3 . This effect indicates a lower $D_{2} / D_{3}$ receptor availability in the putamen MA consumers compared to controls. There was no evidence for publication bias $(\mathrm{p}=0.93)$ and no moderation effects: year of publication $(p=0.06)$, age $(p=0.70)$, gender $(p=0.06)$ or used method $(\mathrm{p}=0.88)$. Regarding the DAT availability, $\mathrm{k}=4$ studies were included with $\mathrm{N}=62$ users and $\mathrm{N}=64$ controls. The summarized effect size was significant with $g=-2.19$ (95\% CI: $[-2.80,-1.57] \mathrm{p}<0.01)$, see Fig. 3. This effect indicates a lower DAT availability in the putamen in MA consumers compared to controls. There was no evidence for publication bias $(p=0.97)$ or moderation effects for year of publication $(p=0.08)$, age $(p=0.11)$, gender $(p=0.12)$ or minimal duration of abstinence $(p=0.67)$. 


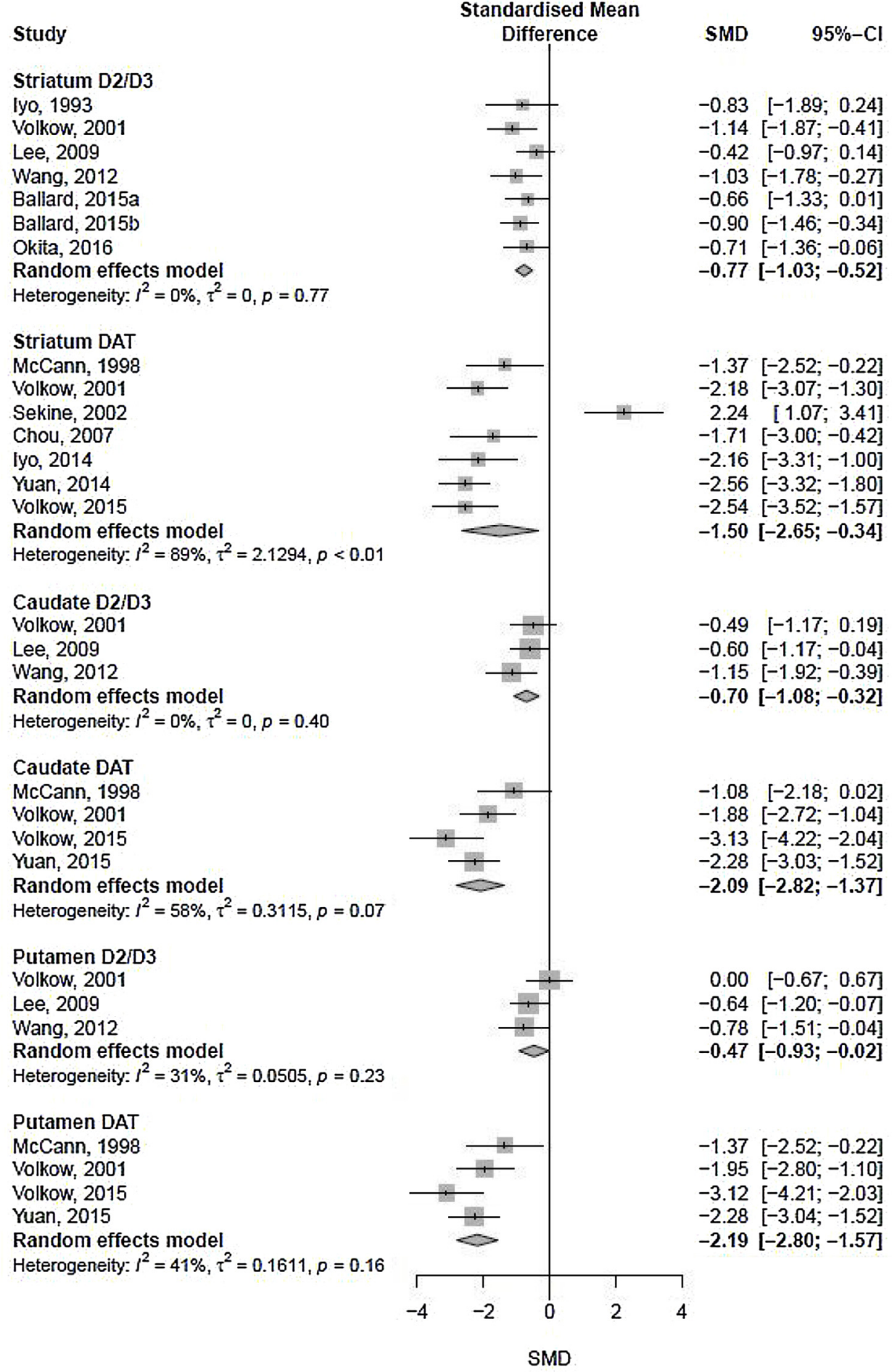

Fig. 3. Forest plot of meta-analysis of striatal dopaminergic function in methamphetamine users vs. nonusers.

\subsection{Amphetamines}

There were no studies regarding the striatal dopamine receptor in amphetamine users (without MA), so only an analysis for DAT was conducted. For DAT availability in the whole striatum, $\mathrm{k}=2$ studies comprising $\mathrm{N}=23$ users and $\mathrm{N}=26$ controls were included. The summarized effect size was significant with $g=-0.95$ (95\% CI: [-1.54, -0.35], $\mathrm{p}<0.01)$, see Fig. 4. This result indicates a lower DAT availability in the striatum of amphetamine users. A regression test for funnel plot asymmetry or moderator analyses were not calculated because of the small number of studies. When investigating the subregions, $\mathrm{k}=2$ studies with $\mathrm{N}=23$ users and $\mathrm{N}=26$ controls were included for the comparison of DAT availability in the caudate. The summarized effect size was significant with $\mathrm{g}=-1.01$ (95\% CI: [-1.61, -0.40] $\mathrm{p}<0.01$ ), see Fig. 4. This result indicates a lower DAT availability in the caudate of amphetamine users. Regression test for funnel plot asymmetry or moderator analyses were not calculated.

For the analysis of DAT availability in putamen, $k=3$ studies were included with $\mathrm{N}=41$ users and $\mathrm{N}=37$ controls. The 


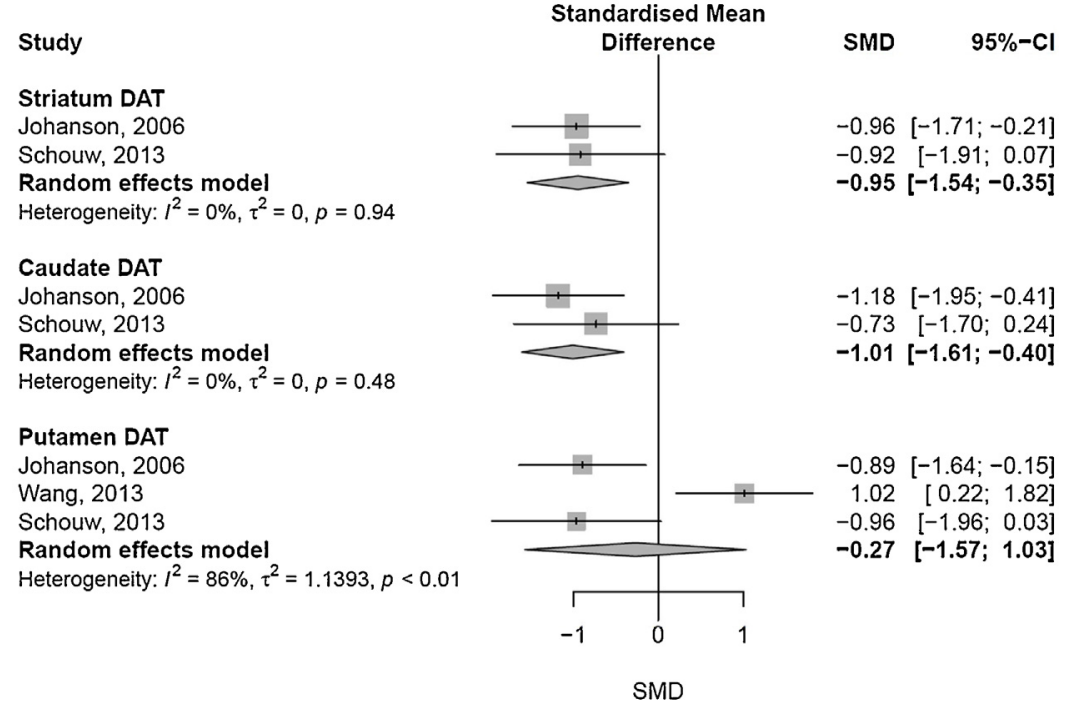

Fig. 4. Forest Plot of meta-analysis of striatal dopaminergic function in amphetamine users vs. non users.

summarized effect size was $\mathrm{g}=-0.27(95 \% \mathrm{CI}$ : [-1.57, 1.03], $\mathrm{p}=0.69)$, see Fig. 4 . There was no evidence for publication bias $(p=0.88)$, or moderation effects for year of publication $(p=0.58)$, age $(p=0.69)$, used method $(p=0.54)$ and minimal duration of abstinence $(p=0.41)$. A significant moderation effect for gender was found $(p=0.01)$, pointing to a stronger negative effect with an increasing ratio of men to the total number of participants.

\section{Discussion}

This meta-analysis is, to our knowledge, the first that investigates, not only dopaminergic changes in the striatum, but also the striatal sub regions caudate and putamen. The influence of possible moderation variables was conducted as well. Current research only reports on partial recovery after two weeks [37] or even after years of abstinence [42]. Our results support the hypothesis of generally lower dopamine receptors in substance abusers [57]. To our knowledge, there are no meta-analyses so far, that also included nicotine. Since nicotine consumption through smoking increases the dopamine content in the synaptic cleft [11], it also represents a psychostimulant substance and can have major impacts on the dopaminergic system. To include nicotine and to show its possible confounding effects is essential since all of the included studies on cocaine, MA and amphetamines except Schrantee et al. [48] allowed nicotine use.

The systematic literature search revealed 39 studies that investigated the striatal dopaminergic systems under stimulant influence. Several significant associations were obtained, which are in line with previously reported research [50]. The main differences of this study to these previous publications is the more refined consideration of specific substances, as well as the striatal region through subregion which allows a more detailed consideration of the specific effects on these areas. Additionally Ashok et al. [50] considered amphetamines and methamphetamines together, while we separated them to take a closer look at the substances individually in order to show the effects of each substance more precisely and to present their respective influence. To this end, the present paper builds up on the very valuable research from Ashok et al. [50] not only in the more diversified contemplation of the sub regions and substances but also by supplementing more research in the meta-analyses for all substances. Studies used for the present analysis have a range in duration of abstinence between three hours and three years, which might be a reason for the mixed results and makes them harder to compare. Another reason for heterogeneity between the studies is the use of different methods (e.g. PET/ SPECT, different radioligands and BPs). Both imaging methods and all tracers measure the high-affinity state of DATs and receptors in in-vivo neuroimaging, which makes the BPs comparable. To strengthen the results of this meta-analysis further research with comparable abstinence levels and methods is recommended. However, we made use of this heterogeneity by conducting - where possible - moderator effects, however these were mainly without significant results. In cocaine users, we found an influence of the used method on the effect size from DAT in the striatum pointing toward stronger effect in SPECT studies compared to PET studies. In addition, with increasing duration of abstinence, the effect on receptor density in the putamen increased.

Regarding methamphetamine, a small effect from the year of publication on DAT in the caudate was found pointing towards stronger effect in newer studies. In amphetamine users a stronger negative effect with increasing percentage of men in the study was found, however the main effect from the meta-analysis was not significant. Publication bias was not detected in our study, however, due to the small number of studies included in the analysis we might not have been able to assess it properly. Looking at the different substances in particular, we come to the result that the summarized effect size of current research shows no significant changes in the dopaminergic system of smokers compared to nonsmokers. Nevertheless, in some studies there is evidence for a decrease of striatal dopamine receptors in men [15] or all participants [17] and decreased DAT in male participants [16]. There are not many studies regarding the effects of nicotine, which shows that further research in this field is mandatory to obtain a more clear perspective. This is especially important considering that most other studies (see Table 1 ) did not check the smoking status of the controls.

Regarding cocaine, this meta-analysis indicates a lower $D_{2} / D_{3}$ receptor availability of cocaine consumers compared to controls and a higher DAT availability in cocaine consumers compared to controls. Since the function of DAT is to terminate the synaptic neurotransmission by the reuptake of dopamine transmitters, chronic inhibition of the DATs may induce a compensatory upregulation. Interestingly, the results are more consistent when looking at the sub regions caudate and putamen. Here, the effects indicate a lower $D_{2} / D_{3}$ receptor availability in cocaine users. Only 
one study was available with data regarding DATs in the sub regions, which indicates higher DAT levels in cocaine users sub regions, which were 10\% (anterior putamen), 17\% (posterior putamen), and $8 \%$ (caudate) higher in the cocaine dependent subjects compared to controls [24].

Our analyses revealed significantly decreased dopamine receptors and transporters in MA users in all regions of interest. This acute effect, which may become chronic [42] could contribute to compensate for the higher dopamine release under drug effects brought about through the higher dopamine release and the simultaneously impaired reuptake thereby causing a general downregulation of receptors. In case of MA consumption over time and repeated administration, lower activation is a consequence [58] and less DAT action will be provided over time. In terms of MA and DATs, studies found a rapid recovery under abstinence [37].

Regarding the striatum, as well as the caudate of amphetamine users both show large significant effect sizes for lower DAT availability in users. For the subregion putamen the effect was not significant but also showed a trend towards lower DAT availability.

We wanted to include studies testing ecstasy and MDMA users, but only one SPECT study about respective substances and changes in the dopaminergic system [59] was found, which indicates significantly lower receptor densities in the frontal and parietal cortex, but significantly higher receptor densities in the occipital cortex of former users. Combining these results might suggest a compensatory upregulation of dopamine receptors in the occipital cortex of former users.

Overall, this meta-analysis provides evidence that there are ongoing changes in the dopaminergic system associated with the use of stimulants. The results of cocaine and MA use both show a downregulation of the receptors in the striatum $(-0.76,-0.77)$ as well as caudate $(-0.54 ;-0.70)$ and putamen $(-0.88,-0.47)$ with cocaine showing a higher effect size on the subregion putamen and MA on caudate. For DAT, the results from the striatum show a higher downregulation after MA use $(-1.5)$ as compared to after amphetamine use (-0.95) and an upregulation after cocaine use (0.66). Results for the subregion caudate and putamen show a higher downregulation after MA use $(-2.09,-2.19)$ then after amphetamine use $(-1.01,-0.27)$. Due to the small number of studies no analyses were conducted for amphetamine and receptors and the subregions after cocaine use. Comparing these results, stronger effect sizes can be seen in DATs compared to receptors, but the results show influences on both structures. The human brain does adapt to changes like these [60], which might be a reason for cognitive impairments like poorer performance in flexibility and memory tasks or spatial working memory in chronic amphetamine users [61] or deficits in attention and verbal memory in current cocaine users [62] as well as mostly poorer performance in all cognitive tasks in different MA user types [63], all compared to healthy controls. The down regulation process in the striatum might be one reason for craving or even lead to relapses [64] because the endogenous dopamine is no longer enough for sufficient stimulation [35].Thus, effects on the dopaminergic system inferred from this analysis may be one reason for addictive behaviors and the development of neurocognitive deficits in stimulant users. To conclude, this metaanalysis shows evidence for changes in the striatal dopaminergic system under stimulant use but it also shows the importance of further neuroimaging research. Longitudinal studies are necessary to find out more about the reversibility and origin of the above-described effects. We also recommend comparing different substances directly to get an overview about different long-term effects. Especially nicotine smoking should be taken more seriously because most studies examining a substance other than nicotine allowed smoking before the examinations (see Table 1). Further studies investigating if preceding nicotine consumption, next to other stimulant intake, can cause crucial differences in scanned brain regions is necessary regarding this particular field of research.

Limitations of this analysis are the sample characteristics such as the abstinence period, the dose and the different tracer in the different groups and different possibilities of stimulant administration. Injecting crosses the blood-brain-barrier faster than inhaling or smoking [65] which might furthermore have worse effects. At the beginning of the examinations all participants were tested for the current use of several drugs aside from the investigated stimulants to eliminate acute influences of other substances, but it cannot be guaranteed that test group participants had consumed only one substance or were rather prone to polytox drug use. There are no tests that can identify all substances on the drug market so we cannot rule out, that some participants were still under drug impact, which in turn might influence the BPs. This shows the difficulty to limit the effects to the examined substance. Additionally most, but not all studies gave information if their user group were current or former users.

Regarding comorbidities, there were many different diagnostic tools used in the studies so the patients went through different exclusion criteria, some of them potentially stricter than others. Additionally different samples, radioligands with different BPs or imaging methods were used in the studies, which might also influence the magnitude of the binding availabilities. Furthermore, most of the studies concentrate on differences in the striatal areas, such as putamen, caudate, dorsal/ ventral striatum or whole striatum. Calculating the means to a whole striatum value or a putamen and caudate value might lead to a loss of the value's precision. Additionally, strict exclusion criteria within the literature search process can lead to bias because of the exclusion of valuable information. This is one reason why additional information was included, where possible, to calculate moderation analyses. Ultimately, drug addiction is a complex process involving many parts of the brain and it is not clear if changes are caused by stimulant use.

\section{Conclusion}

There is evidence for a reduction of dopamine receptors from cocaine, MA and amphetamines, a reduction of DAT from MA and amphetamines, as well as for a higher DAT availability after cocaine use in the striatal systems. There was no distinct evidence for dopaminergic changes after nicotine consumption.

\section{Acknowledgements}

We thank Mrs. Dr. Kathrin Halfter for providing language help. LP and FK are employed and funded by the German Federal Ministry of Health (project: ZMVI1-2516DSM216).

\section{Appendix A. Supplementary data}

Supplementary material related to this article can be found, in the online version, at doi:https://doi.org/10.1016/j. eurpsy.2019.03.003.

\section{References}

[1] United Nations, Office on Drugs and Crime. World drug report 2017. 1st edn. 2017 Vienna.

[2] European Monitoring Centre for Drugs and Drug Addiction. The state of the drugs problem in Europe. Luxembourg: European Union; 2017.

[3] Sulzer D, Sonders MS, Poulsen NW, et al. Mechanisms of neurotransmitter release by amphetamines: a review. Prog Neurobiol 2005;75(6):406-33, doi: http://dx.doi.org/10.1016/j.pneurobio.2005.04.003.

[4] Barr AM, Panenka WJ, MacEwan GW, et al. The need for speed: an update on methamphetamine addiction. J Psychiatry Neurosci 2006;31(5):301-13. 
[5] Volkow ND, Fowler JS, Wang G-J, et al. Distribution and pharmacokinetics of methamphetamine in the human body: clinical implications. PLoS One 2010;5 (12)e15269, doi:http://dx.doi.org/10.1371/journal.pone.0015269.

[6] Ezzati M, Lopez AD. Measuring the accumulated hazards of smoking: global and regional estimates for 2000. Tob Control 2003;12(1):79-85.

[7] Zhang H, Sulzer D. Frequency-dependent modulation of dopamine release by nicotine. Nat Neurosci 2004;7(6):581-2, doi:http://dx.doi.org/10.1038/ nn1243.

[8] Salokangas RK, Vilkman H, Ilonen T, et al. High levels of dopamine activity in the basal ganglia of cigarette smokers. Am J Psychiatry 2000;157(4):632-4, doi:http://dx.doi.org/10.1176/appi.ajp.157.4.632.

[9] Brody AL. Functional brain imaging of tobacco use and dependence. J Psychiatr Res 2006;40(5):404-18, doi:http://dx.doi.org/10.1016/j. jpsychires.2005.04.012.

[10] Partridge JG, Apparsundaram S, Gerhardt GA, et al. Nicotinic acetylcholine receptors interact with dopamine in induction of striatal long-term depression. J Neurosci 2002;22(7):2541-9, doi:http://dx.doi.org/10.1523/ JNEUROSCI.22-07-02541.2002.

[11] Wonnacott S, Sidhpura N, Balfour DJK. Nicotine: from molecular mechanisms to behaviour. Curr Opin Pharmacol 2005;5(1):53-9, doi:http://dx.doi.org/ 10.1016/j.coph.2004.12.002.

[12] Schultz W, Dayan P, Montague PR. A neural substrate of prediction and reward. Science 1997;275(5306):1593-9.

[13] Simon SL, Dacey J, Glynn S, et al. The effect of relapse on cognition in abstinent methamphetamine abusers. J Subst Abuse Treat 2004;27(1):59-66, doi:http:// dx.doi.org/10.1016/j.jsat.2004.03.011.

[14] dela Peña I, Gevorkiana R, Shi W-X. Psychostimulants affect dopamine transmission through both dopamine transporter-dependent and independent mechanisms. Eur J Pharmacol 2015;764:562-70, doi:http://dx. doi.org/10.1016/j.ejphar.2015.07.044.

[15] Brown AK, Mandelkern MA, Farahi J, et al. Sex differences in striatal dopamine D2/D3 receptor availability in smokers and non-smokers. Int J Neuropsychopharmacol 2012;15(7):989-94, doi:http://dx.doi.org/10.1017/ S1461145711001957.

[16] Yang YK, Yao WJ, Yeh TL, et al. Decreased dopamine transporter availability in male smokers - a dual isotope SPECT study. Prog Neuropsychopharmacol Biol Psychiatry 2008;32(1):274-9, doi:http://dx.doi.org/10.1016/j. pnpbp.2007.08.018.

[17] Dagher A, Bleicher C, Aston JA, et al. Reduced dopamine D1 receptor binding in the ventral striatum of cigarette smokers. Synapse 2001;42(1):48-53, doi: http://dx.doi.org/10.1002/syn.1098.

[18] Staley JK, Krishnan-Sarin S, Zoghbi S, et al. Sex differences in 123Ibeta-CIT SPECT measures of dopamine and serotonin transporter availability in healthy smokers and nonsmokers. Synapse 2001;41(4):275-84, doi:http://dx.doi.org/ 10.1002/syn.1084.

[19] Yang YK, Yao WJ, McEvoy JP, et al. Striatal dopamine D2/D3 receptor availability in male smokers. Psychiatry Res 2006;146(1):87-90, doi:http://dx. doi.org/10.1016/j.pscychresns.2005.09.008.

[20] Martinez D, Broft A, Foltin RW, et al. Cocaine dependence and d2 receptor availability in the functional subdivisions of the striatum: relationship with cocaine-seeking behavior. Neuropsychopharmacology 2004;29(6):1190-202, doi:http://dx.doi.org/10.1038/sj.npp.1300420.

[21] Martinez D, Carpenter KM, Liu F, et al. Imaging dopamine transmission in cocaine dependence: link between neurochemistry and response to treatment. Am J Psychiatry 2011;168(6):634-41, doi:http://dx.doi.org/10.1176/ appi.ajp.2010.10050748.

[22] Martinez D, Slifstein M, Narendran R, et al. Dopamine D1 receptors in cocaine dependence measured with PET and the choice to self-administer cocaine. Neuropsychopharmacology 2009;34(7):1774-82, doi:http://dx.doi.org/ 10.1038/npp.2008.235.

[23] Wiers CE, Shokri-Kojori E, Cabrera E, et al. Socioeconomic status is associated with striatal dopamine D2/D3 receptors in healthy volunteers but not in cocaine abusers. Neurosci Lett 2016;617:27-31, doi:http://dx.doi.org/10.1016/ j.neulet.2016.01.056.

[24] Crits-Christoph P, Newberg A, Wintering N, et al. Dopamine transporter levels in cocaine dependent subjects. Drug Alcohol Depend 2008;98(1-2):70-6, doi: http://dx.doi.org/10.1016/j.drugalcdep.2008.04.014.

[25] Jacobsen LK, Staley JK, Malison RT, et al. Elevated central serotonin transporte binding availability in acutely abstinent cocaine-dependent patients. Am J Psychiatry 2000;157(7):1134-40, doi:http://dx.doi.org/10.1176/appi. ajp.157.7.1134.

[26] Malison RT, Best SE, van Dyck CH, et al. Elevated striatal dopamine transporters during acute cocaine abstinence as measured by 123I beta-CIT SPECT. Am J Psychiatry 1998;155(6):832-4, doi:http://dx.doi.org/10.1176/ajp.155.6.832.

[27] Matuskey D, Gallezot J-D, Pittman B, et al. Dopamine $D_{3}$ receptor alterations in cocainedependent humans imaged with ${ }^{11} \mathrm{C}(+)$ PHNO. Drug Alcohol Depend 2014;139:100-5, doi:http://dx.doi.org/10.1016/j.drugalcdep.2014.03.013.

[28] Narendran R, Martinez D, Mason NS, et al. Imaging of dopamine D2/3 agonist binding in cocaine dependence: a 11CNPA positron emission tomography study. Synapse 2011;65(12):1344-9, doi:http://dx.doi.org/10.1002/syn.20970.

[29] Wang G], Volkow ND, Fowler JS, et al. Cocaine abusers do not show loss of dopamine transporters with age. Life Sci 1997;61(11):1059-65.

[30] Matuskey D, Gaiser EC, Gallezot J-D, et al. A preliminary study of dopamine D2/ 3 receptor availability and social status in healthy and cocaine dependen humans imaged with (11)C(+)PHNO. Drug Alcohol Depend 2015;154:167-73, doi:http://dx.doi.org/10.1016/j.drugalcdep.2015.06.039.
[31] Ballard ME, Dean AC, Mandelkern MA, et al. Striatal dopamine D2/D3 receptor availability is associated with executive function in healthy controls but not methamphetamine users. PLoS One 2015;10(12)e0143510, doi:http://dx.doi. org/10.1371/journal.pone.0143510.

[32] Lee B, London ED, Poldrack RA, et al. Striatal dopamine $\mathrm{d} 2 / \mathrm{d} 3$ receptor availability is reduced in methamphetamine dependence and is linked to impulsivity. J Neurosci 2009;29(47):14734-40, doi:http://dx.doi.org/10.1523/ JNEUROSCI.3765-09.2009.

[33] Ballard ME, Mandelkern MA, Monterosso JR, et al. Low dopamine D2/D3 receptor availability is associated with steep discounting of delayed rewards in methamphetamine dependence. Int J Neuropsychopharmacol 2015;18(7): pyu119, doi:http://dx.doi.org/10.1093/ijnp/pyu119.

[34] Okita K, Ghahremani DG, Payer DE, et al. Relationship of alexithymia ratings to dopamine D2-type receptors in anterior cingulate and insula of healthy control subjects but not methamphetamine-dependent individuals. Int J Neuropsychopharmacol 2016;19(5), doi:http://dx.doi.org/10.1093/ijnp/pyv129.

[35] Wang G-J, Volkow ND, Wigal T, et al. Long-term stimulant treatment affects brain dopamine transporter level in patients with attention deficit hyperactive disorder. PLoS One 2013;8(5)e63023, doi:http://dx.doi.org/10.1371/journal. pone.0063023.

[36] Sekine Y, Iyo M, Ouchi Y, et al. Methamphetamine-related psychiatric symptoms and reduced brain dopamine transporters studied with PET. Am J Psychiatry 2001;158(8):1206-14, doi:http://dx.doi.org/10.1176/appi. ajp.158.8.1206.

[37] Chou Y-H, Huang W-S, Su T-P, et al. Dopamine transporters and cognitive function in methamphetamine abuser after a short abstinence: a SPECT study. Eur Neuropsychopharmacol 2007;17(1):46-52, doi:http://dx.doi.org/10.1016/ j.euroneuro.2006.05.002.

[38] Iyo M, Sekine Y, Mori N. Neuromechanism of developing methamphetamine psychosis: a neuroimaging study. Ann N Y Acad Sci 2004;1025:288-95, doi: http://dx.doi.org/10.1196/annals.1316.036.

[39] McCann UD, Wong DF, Yokoi F, et al. Reduced striatal dopamine transporter density in abstinent methamphetamine and methcathinone users: evidence from positron emission tomography studies with 11CWIN-35,428. J Neurosci 1998;18(20):8417-22.

[40] Yuan J, Liu XD, Han M, et al. Comparison of striatal dopamine transporter levels in chronic heroin-dependent and methamphetamine-dependent subjects. Addict Biol 2017;22(1):229-34, doi:http://dx.doi.org/10.1111/adb.12271.

[41] Yuan J, Lv R, Robert Brašić J, et al. Dopamine transporter dysfunction in Han Chinese people with chronic methamphetamine dependence after a shortterm abstinence. Psychiatry Res 2014;221(1):92-6, doi:http://dx.doi.org/ 10.1016/j.pscychresns.2013.11.005.

[42] Volkow ND, Chang L, Wang G], et al. Association of dopamine transporter reduction with psychomotor impairment in methamphetamine abusers. Am J Psychiatry 2001;158(3):377-82, doi:http://dx.doi.org/10.1176/appi. ajp.158.3.377.

[43] Volkow ND, Chang L, Wang GJ, et al. Low level of brain dopamine D2 receptors in methamphetamine abusers: association with metabolism in the orbitofrontal cortex. Am J Psychiatry 2001;158(12):2015-21, doi:http://dx.doi. org/10.1176/appi.ajp.158.12.2015.

[44] Volkow ND, Wang G-J, Smith L, et al. Recovery of dopamine transporters with methamphetamine detoxification is not linked to changes in dopamine release. Neuroimage 2015;121:20-8, doi:http://dx.doi.org/10.1016/j. neuroimage.2015.07.035

[45] Iyo M, Nishio M, Itoh T, et al. Dopamine D2 and serotonin S2 receptors in susceptibility to methamphetamine psychosis detected by positron emission tomography. Psychiatry Res 1993;50(4):217-31.

[46] Johanson C-E, Frey KA, Lundahl LH, et al. Cognitive function and nigrostriatal markers in abstinent methamphetamine abusers. Psychopharmacology (Berl) 2006;185(3):327-38, doi:http://dx.doi.org/10.1007/s00213-006-0330-6.

[47] Schrantee A, Ferguson B, Stoffers D, et al. Effects of dexamphetamine-induced dopamine release on resting-state network connectivity in recreational amphetamine users and healthy controls. Brain Imaging Behav 2016;10 (2):548-58, doi:http://dx.doi.org/10.1007/s11682-015-9419-z.

[48] Schrantee A, Václavủ L, Heijtel DFR, et al. Dopaminergic system dysfunction in recreational dexamphetamine users. Neuropsychopharmacology 2015;40 (5):1172-80, doi:http://dx.doi.org/10.1038/npp.2014.301.

[49] Schouw MLJ, Caan MWA, Geurts HM, et al. Monoaminergic dysfunction in recreational users of dexamphetamine. Eur Neuropsychopharmacol 2013;23 (11):1491-502, doi:http://dx.doi.org/10.1016/j.euroneuro.2013.01.005.

[50] Ashok AH, Mizuno Y, Volkow ND, et al. Association of stimulant use with dopaminergic alterations in users of cocaine, amphetamine, or methamphetamine: a systematic review and meta-analysis. JAMA Psychiatry 2017:74(5):511-9, doi:http://dx.doi.org/10.1001/jamapsychiatry.2017.0135.

[51] Innis RB, Cunningham VJ, Delforge J, et al. Consensus nomenclature for in vivo imaging of reversibly binding radioligands. J Cereb Blood Flow Metab 2007;27 (9):1533-9, doi:http://dx.doi.org/10.1038/sj.jcbfm.9600493.

[52] Egerton A, Demjaha A, McGuire P, et al. The test-retest reliability of 18F-DOPA PET in assessing striatal and extrastriatal presynaptic dopaminergic function. Neuroimage 2010;50(2):524-31, doi:http://dx.doi.org/10.1016/j. neuroimage.2009.12.058.

[53] Cochran WG, Wishart J. The distribution of quadratic forms in a normal system, with applications to the analysis of covariance. Math Proc Camb Phil Soc 1934;30(02):178, doi:http://dx.doi.org/10.1017/S0305004100016595.

[54] Viechtbauer W. Conducting meta-analyses in $r$ with the metafor package. J Stat Soft 2010;36(3), doi:http://dx.doi.org/10.18637/jss.v036.i03. 
[55] Egger M, Davey Smith G, Schneider M, et al. Bias in meta-analysis detected by a simple, graphical test. BMJ 1997;315(7109)629-34 Rohatgi A WebPlotDigitzer.

[56] Nutt DJ, Lingford-Hughes A, Erritzoe D, et al. The dopamine theory of addiction: 40 years of highs and lows. Nat Rev Neurosci 2015;16(5):305-12, doi:http://dx.doi.org/10.1038/nrn3939.

[57] Wise RA, Bozarth MA. Brain mechanisms of drug reward and euphoria. Psychiatr Med 1985;3(4):445-60.

[58] Reneman L, Booij J, Lavalaye J, et al. Use of amphetamine by recreational users of ecstasy (MDMA) is associated with reduced striatal dopamine transporter densities: a 123Ibeta-CIT SPECT study-preliminary report.

Psychopharmacology (Berl) 2002;159(3):335-40, doi:http://dx.doi.org/ 10.1007/s00213-001-0930-0.

[59] Björklund A, Dunnett SB. Dopamine neuron systems in the brain: an update. Trends Neurosci 2007;30(5):194-202, doi:http://dx.doi.org/10.1016/j. tins.2007.03.006.

[60] Ornstein T. Profiles of cognitive dysfunction in chronic amphetamine and heroin abusers. Neuropsychopharmacology 2000;23(2):113-26, doi:http://dx. doi.org/10.1016/S0893-133X(00)00097-X.
[61] Woicik PA, Moeller SJ, Alia-Klein N, et al. The neuropsychology of cocaine addiction: recent cocaine use masks impairment. Neuropsychopharmacology 2009;34(5):1112-22, doi:http://dx.doi.org/10.1038/npp.2008.60.

[62] Proebstl L, Kamp F, Koller G, et al. Cognitive Deficits in Methamphetamine Users: How Strong is The Evidence? Pharmacopsychiatry 2018;51(6):243-50, doi:http://dx.doi.org/10.1055/s-0043-123471.

[63] Hartz DT, Frederick-Osborne SL, Galloway GP. Craving predicts use during treatment for methamphetamine dependence: a prospective, repeatedmeasures, within-subject analysis. Drug Alcohol Depend 2001;63(3):269-76.

[64] Härtel-Petri R. Crystal-Meth als herausforderung für das suchthilfesystem klinische Empfehlungen. Suchttherapie 2016;17(01):10-6, doi:http://dx.doi. org/10.1055/s-0035-1559657.

[65] Wang GJ, Smith L, Volkow ND, Telang F, Logan J, Tomasi D, et al. Decreased dopamine activity predicts relapse in methamphetamine abusers. Mol Psychiatry 2012;17(9):918-25, doi:http://dx.doi.org/10.1038/mp.2011.86. 